\title{
O mediador de conflitos escolares: experiências na América do Sul
}

\author{
Beatris Cristina Possato \\ Universidade Cidade de São Paulo - São Paulo - SP - Brasil \\ Antonio J. Rodríguez-Hidalgo \\ Universidade de Córdoba - Córdoba - Espanha \\ Rosario Ortega-Ruiz \\ Universidade de Córdoba - Córdoba - Espanha \\ Dirce Djanira Pacheco e Zan \\ Universidade Estadual de Campinas - Campinas - SP - Brasil
}

\begin{abstract}
Resumo
Este artigo discute a mediação de conflitos, como forma para amenizar as violências escolares, que nasce nos meios jurídicos nos Estados Unidos, difunde-se pela Europa e posteriormente pela América do Sul, inclusive no Brasil. Foi realizada uma pesquisa bibliográfica, buscando documentos oficiais, investigações e livros publicados sobre essas experiências em diversos países. Há uma expansão de programas e projetos que utilizam a mediação de conflitos ao longo da última década nos países da América do Sul. Analisando esses programas podemos perceber que há muito investimento nesse tipo de estratégia, que é apenas uma entre outras para auxiliar as escolas com a problemática da violência. Mesmo assim, a mediação de conflitos torna-se elemento central dos programas educacionais. Para definir-se a melhor atuação em determinada sociedade ou realidade escolar seria necessária uma investigação extensa para avaliar a melhor estratégia, porém, a mediação de conflitos vem expandindo-se cada vez mais, indiscriminadamente.
\end{abstract}

Palavras-chave: Mediação; conflito; violência escolar.

\section{The mediator of school conflicts: experiences in South America}

\begin{abstract}
This article discusses the conflict mediation as a way to ease the school violence, that was born in legal circles in the United States, diffuses through Europe and later in South America, including Brazil. The literature search was conducted, seeking official documents, investigations and books published on these experiences in different countries. There is an expansion of programs and projects that use the mediation of conflicts over the past decade in the countries of South America. By analyzing these programs it was possible to notice that there is a lot of investment in this type of strategy, which is only one among others to assist schools with the problem of violence. Nevertheless, conflict mediation becomes the central element of the educational programs. To set up the best performance in a given society or school reality would be an extensive research needed to assess what would be the best strategy, however, conflict mediation is expanding increasingly indiscriminately.
\end{abstract}

Keywords: Mediation; Conflict; school violence.

\section{El mediador de conflictos escolares: experiencias en América del Sur}

\section{Resumen}

Este artículo discute la mediación de conflictos, como forma para amenizar las violencias escolares, que nace en los medios jurídicos en los Estados Unidos, se difunde por Europa y posteriormente por América del Sur, incluso en Brasil. Se realizó una investigación bibliográfica, buscando documentos oficiales, investigaciones en libros publicados sobre esas experiencias en diversos países. Hay una expansión de programas y proyectos que utilizan la mediación de conflictos a lo largo de la última década en los países de América del Sur. Analizando esos programas podemos percibir que hay mucha inversión en ese tipo de estrategia, que es sólo una entre otras para auxiliar las escuelas con la problemática de la violencia. Aun así, la mediación de conflictos se vuelve elemento central de los programas educacionales. Para definirse la mejor actuación en determinada sociedad o realidad escolar sería necesaria una investigación extensa para evaluar la mejor estrategia, pero, la mediación de conflictos viene expandiéndose cada vez más, indiscriminadamente.

Palabras clave: Mediación; Conflicto; Violencias escolares. 


\section{Introdução}

Bem sabemos que a boa convivência não é sinônimo de ausência de conflitos. O conflito é inerente às relações humanas. Maffesoli (1987) nos diz que na sociedade há uma "harmonia conflitual", ou seja, toda harmonia possui uma dose de conflito. É preciso lidar com a heterogeneidade, realizar acordos, fazer negociações. Desse modo, não há como objetivar eliminar os conflitos por completo e nem pode ser essa a escolha quando se está comprometido com a construção de uma sociedade democrática e participativa.

O conflito é uma situação que surge entre pelo menos dois ou mais protagonistas, na qual se produz uma confrontação de interesses (Fernández, 1998). Deste choque de interesses surgem posições contrapostas em primeira instância. Se os conflitos são consubstanciais aos sistemas de relações humanas, as confrontações não têm motivos para conduzir a manifestações extremas de violência (Ortega \& Rodríguez, 2003). Na medida em que os protagonistas usam instrumentos apropriados, como a negociação verbal, em busca de uma solução que contemple tanto a situação dos distintos participantes como a maior parte possível de seus interesses, se avançará para uma resolução satisfatória do conflito (Fernández, 1998; Del Rey, Sánchez, \& Ortega, 2004).

Parafraseando Madalena Freire (1992), o conflito é uma oportunidade da ruptura do estabelecido para que se construa algo novo. Assim, somente pelo conflito (compreendido em sentido amplo) há o desenvolvimento dos indivíduos, dos grupos, das instituições. Embora os conflitos façam parte de nossa vida e inclusive representem uma parte construtiva das relações humanas, continuam sendo considerados pelas pessoas e instituições como algo negativo, anormal, que deve ser expurgado da sociedade. Do mesmo modo, na escola, como instituição educativa, não poderia ser diferente. Silva (2011) destaca que os conflitos são parte de nossa natureza social e humana, mas mesmo assim muitas escolas buscam ocultar os conflitos, estabelecendo uma relação negativa com eles. Em seu clássico trabalho intitulado "Currículo e Ideologia”, Apple (2006) aponta para uma estratégia histórica da instituição escolar em contribuir para difundir uma compreensão do conflito como algo a ser eliminado e evitado. Como observado em suas pesquisas, o autor relata que há uma "quase completa falta de tratamento ou mesmo referência ao conflito como algo que seja de interesse social ou como categoria de pensamento nos currículos mais utilizados ou na maioria das salas de aula observadas..." (p. 139).

Contrário a esse movimento, reconhecemos que existe um crescente número de investigadores e teóricos da educação que compreendem o conflito no contexto escolar como uma oportunidade para a mudança, o enriquecimento e o desenvolvimento psicossocial (Ortega \& Del Rey, 2003). Os conflitos na convivência oferecem continuamente oportunidades para descobrir ao outro e para conhecer-se a si mesmo, para experimentar novas formas de relação e entendimento, e em consequência, para desenvolver nossa identidade pessoal (Del Rey \& cols., 2004) e nossa identidade cultural como membros de um grupo social (Ortega,
Rodríguez, \& Larrasoain, 2004). Surge assim na escola, a necessidade de articular meios para contribuir para a resolução e superação de conflitos de uma forma dialogada, buscando prevenir a violência e os desequilíbrios de poder.

Silva (2011) destaca, referindo-se aos conflitos, que os "contextos educativos são contextos de excelência para os abordar e trabalhar, numa perspectiva integradora, de desenvolvimento pessoal e social e, nesse sentido, com um forte pendor educacional e formador" (p.256). Dependendo do modelo escolar, em diferentes países se desenvolvem programas e inclusive participam diretamente na escola pessoas com funções específicas, muitas vezes dirigidas à busca de estratégias de formação e intervenção em relação aos conflitos, sendo algumas das experiências mais alargadas e populares as de mediação escolar.

A mediação escolar tem sua antessala na mediação de conflitos em contextos não escolares. A mediação de conflitos nasce nos meios jurídicos nos Estados Unidos no início da década de 1970, em que havia a necessidade de se encontrar mecanismos alternativos de resolução de conflitos, que fossem mais baratos e menos formais (Zampa, 2009). $\mathrm{Na}$ mesma época surgem experiências na França com a mediação de conflitos. Em meados da década de 1980, a mediação passa a estender-se a outros contextos como a comunidade, a família e a mediação penal. A mediação começa a distanciar-se da resolução de litígios; porém, possui elementos de práticas como a conciliação e a arbitragem do campo jurisdicional. Na década de 1990, surgem práticas alternativas de resolução de conflitos e diversos projetos para mediadores em diferentes países (Bonafé-Schmitt, 2009).

De acordo com Alzate (1999), no campo educacional a mediação escolar se destaca na década de 1980 nos Estados Unidos, quando os Centros de Mediação Comunitária, criados em meados de 1970, passam a receber numerosos casos de crianças e jovens em situações de disputa no contexto escolar. Uma boa parte destes conflitos poderia partir ou desembocar em situações de discriminação étnico-cultural e de violência (Monks, Ortega-Ruiz, \& Rodríguez-Hidalgo, 2008; Rodríguez, 2010). Nos anos 80 grupos étnico-culturais minoritários eram alvo nas escolas da discriminação racial por parte de seus professores e dos outros alunos. Segundo Feshbach (2001), os problemas ligados ao fator diferencial da diversidade étnica - que nós contemplaríamos como diversidade étnico-cultural e socioeconômica - se estendem a muitas sociedades multiétnicas - desde nossa perspectiva, multiculturais - no contexto global.

Em 1982, os Community Boards de San Francisco impulsionam a colaboração entre o sistema educacional e os Centros de Mediação Comunitária. Gradualmente, as experiências com a mediação de conflitos nos meios escolares ampliam-se por diversos países e atualmente é possível encontrar experiências na Europa em países como França, Grã-Bretanha, Suíça, Bélgica, Polônia, Alemanha, Espanha, entre outros; também na Nova Zelândia, Austrália, Canadá e países da América Latina, como Argentina, Chile, Equador, Colômbia, Venezuela, México, Porto Rico, Brasil, entre outros (Alzate, 2009). 


\section{A mediação consiste em}

uma negociação com a intervenção de um terceiro neutral, baseada nos princípios da voluntariedade das partes, da neutralidade e imparcialidade do terceiro (mediador) e na confidencialidade do processo, a fim de que as partes em litígio encontrem soluções que sejam mutuamente satisfatórias. (Morgado \& Oliveira, 2009, p.48).

Alguns autores podem negar que a mediação seja um processo de negociação; contudo, estamos convencidos de que a mediação é negociação, sobretudo uma negociação psicossocial, ou seja, envolve o que ofereço e o que perco, o que faço a partir de minha própria decisão, de meu próprio posicionamento, sem ser imposto por outra pessoa. O princípio de voluntariedade seria devido ao fato dos protagonistas no processo, no caso os envolvidos no conflito, desejarem que a mediação aconteça e participem dela voluntariamente. Na verdade, a mediação deveria ser "solicitada pelos protagonistas ou sugerida pela instituição ou grupo de responsáveis pelo programa e nunca é realizada sem o consentimento ou aceitação plena das pessoas em conflito, que serão protagonistas do processo" (Ortega-Ruiz \& Del Rey, 2002, p.161). A imparcialidade faz com que o mediador seja um sujeito que apenas conduz a mediação, sem tender a uma das partes. A confidencialidade é relativa ao fato de a mediação ser um processo que apenas deve envolver mediador e protagonistas do conflito (Morgado \& Oliveira, 2009; Ortega-Ruiz \& Del Rey, 2002). A solução é construída, negociada pelas partes, que devem obter um benefício, evitando-se uma postura antagônica de "perdedor-ganhador" (Seijo \& González, 2008).

Porém, esse papel de neutralidade não significa que o mediador apenas escute passivamente as falas dos protagonistas do conflito. De acordo com sua formação, deverá conduzir a mediação para que os envolvidos no processo construam um acordo. Por meio da mediação há a oportunidade da palavra para os envolvidos no processo e o mediador irá escutar, avaliando as possíveis estratégias consensuais para que o conflito seja amenizado e que as partes obtenham aquilo de que necessitam (Aréchaga, Brandoni, \& Finkelstein, 2004). O mediador não é aquele que dá as respostas a um conflito, ele não deve fornecer "soluções"; é o responsável por oportunizar um espaço onde o conflito seja reelaborado, reformulado e repensado de maneira construtiva (Zampa, 2009).

Quando um programa de Mediação de Conflitos é introduzido em uma realidade escolar, há de se ter cuidado. Ortega-Ruiz e Del Rey (2002) nos alertam quanto ao risco de "se converter a convivência num cenário de transtornos do comportamento e na tendência a introduzir, na instituição escolar, um modelo clínico que não é necessário, nem conveniente" (p.144). Assim, o auxílio que a mediação poderia oferecer às pessoas com dificuldade de resolver seus conflitos por elas mesmas não pode se tornar um auxílio a uma patologia, mas o auxílio de um especialista a desenvolver a formação para a convivência. Deste modo, é imprescindível que esse profissional, o mediador, seja um especialista e que sua formação seja específica nas técnicas de mediação de conflitos.

A formação é indispensável visto que a equipe de mediação pode e deve ser constituída por responsáveis pelos alunos (familiares), comunidade e alunos, ou seja, pessoal não docente. A mediação não pode ser desempenhada por pessoas da equipe docente e gestora para que, entre outros aspectos, se mantenha a neutralidade, bem como por pessoas não foram formadas para tal finalidade (Ortega-Ruiz \& Del Rey, 2002). Os membros da equipe de mediação não são juízes e não deverão impor soluções ou tentar eleger uma verdade, pois devem favorecer a colaboração e o diálogo (Seijo \& González, 2008). Com uma gama ampla de possíveis mediadores e de situações para serem gerenciadas, sem dúvida a formação é um fator preponderante para auxiliar nas práticas dos mediadores.

Há uma série de práticas que podem ser seguidas pelo mediador dependendo da natureza do conflito e da postura do mediador. Como exemplo, é possível citar a pesquisa de Deborah Kolb que narra a trajetória de 12 mediadores que utilizam técnicas diferenciadas de mediação (Kolb, 1994). A mediação atualmente possui práticas diferenciadas e seus contextos podem ser mais amplos do que meramente técnicos e instrumentais. Algumas práticas igualmente podem ser informais e ter relação com posturas políticas e/ou religiosas (Silva, 2011).

A trajetória histórica da mediação numa sociedade em constante mudança pode fornecer indícios para compreender as práticas diferenciadas, que segundo Bonafé-Schmitt (2009), passa de uma competência em gestão e resolução de conflitos para o enfoque da comunicação, da educação e da segurança, o que amplia a confusão conceitual. Importante é saber que em todas as práticas e para todas as formações o uso do diálogo, da comunicação é o principal elemento nos tempos atuais (Littlejohn \& Domenici, 1999; Vecchi \& Grego, 1999; Seijo, 2001). Porém, a mediação é apenas um instrumento a mais que pode ser utilizado nas escolas, em situações específicas, para o trabalho com os conflitos. Segundo Ortega-Ruiz e Del Rey (2002), essa estratégia não pode ser considerada de modo leviano. "A consideração da mediação como uma estratégia específica e a formação do(a) mediador(a) escolar, bem como o controle sobre o processo concreto de cada mediação garantem que esta tenha o sucesso que se busca" (Ortega-Ruiz \& Del Rey, 2002, p. 149).

O êxito da mediação igualmente depende do envolvimento de todos os sujeitos do contexto escolar. De acordo com Morgado e Oliveira (2009), a mediação deve estar em um contexto significativo, sobretudo para crianças e jovens que participem do projeto. A sensibilização de todos os envolvidos no processo de mediação se faz necessária e necessita ser compatível com o processo de aprendizagem e, principalmente, é importante que não haja incoerência entre as ações do mediador e as atitudes da equipe docente e gestora. Para que um projeto de Mediação de Conflitos se implemente é necessário que haja uma intervenção or- 
ganizacional envolvendo todas as instâncias da escola e suas variadas relações/conflitos dentro e fora da sala de aula (aluno-aluno, professor-aluno, professor-diretor etc.). $\mathrm{E}$ esse "enfoque escolar global de transformação de conflitos" (Alzate, 1999) vai além da intervenção organizacional dos conflitos, intervindo não apenas no sistema disciplinar, mas também no currículo (quando os conceitos e as técnicas da mediação poderiam ser incluídos nas disciplinas escolares), na pedagogia (jogos cooperativos, debates, workshops sobre a mediação), enfim, na cultura escolar que envolva escola, família e comunidade. Para Morgado e Oliveira (2009), além do envolvimento, seria necessário que se implementasse uma organização de equipe multidisciplinar de mediadores, formados em diversas áreas de conhecimento: psicologia, sociologia, serviço social, pedagogia, entre outras.

Garcia Costoya (2004) relata, referindo-se ao "Programa Nacional de Mediación Escolar" (Argentina), que para implementar um projeto de Mediação de Conflitos é necessário que haja, após o diagnóstico das necessidades, a sensibilização dos participantes para que se envolvam com o projeto e a criação de uma equipe de apoio (envolvendo docentes e não docentes, pais e alunos). Essa equipe irá acompanhar o projeto, coordenar junto à equipe externa multidisciplinar de técnicos-mediadores, participar, monitorar e dar apoio em todas as ações, avaliar e propor ajustes do processo. Essa equipe auxiliará na seleção e formação de alunos mediadores e se reunirá regularmente, no intuito de coordenar conjuntamente a equipe de alunos mediadores e analisar as dificuldades encontradas. Enfim, propõe que haja uma avaliação e flexibilidade constante do processo de mediação para se adequar aos problemas encontrados.

Como já discutido, as práticas em mediação de conflitos são múltiplas e, algumas vezes, aproximam-se do que teoricamente é proposto como ideal e outras vezes, nem tanto. Em diversos países do mundo, programas em políticas públicas são criados para a inserção da mediação nas escolas ou em contextos educativos. Na Europa, há uma consolidação desses programas nos sistemas educativos. Em Portugal, por exemplo, Freire (2010) descreve o processo de implantação da mediação no campo educativo que está amparado em três campos distintos "a mediação socioeducativa ou sociocultural muito associada à problemática da exclusão social, a mediação de conflitos interpessoais, ligada a problemática da indisciplina e da conflitualidade no interior das escolas e, simultaneamente com estas duas, a da formação de mediadores" (Freire, 2010, p.68).

A vertente da mediação socioeducativa ou sociocultural, projeto que surge na década de 1990, visa à contribuição para o sucesso educativo dos alunos com dificuldades de adaptação na escola, com um trabalho que envolve escola, família e comunidade. Sendo uma estratégia política para a diminuição dos problemas de abandono escolar e exclusão social, nasce num contexto em que Portugal participa de projetos, sob a pressão de políticas europeias, na tentativa de arrecadar fundos comunitários. Já a mediação de conflitos surge, naquele país, entre 2000 e 2001, no interior das próprias escolas. A busca é por encontrar estratégias para li- dar com a indisciplina e a conflitualidade excessivas (Freire, 2010). Freire tece uma crítica a esses projetos, que embora bem regulamentados legalmente, não puderam fazer com que os mediadores, socioeducativos e de conflitos, fossem inseridos na totalidade da escola, tornando-se profissionais à parte do sistema.

Já na Espanha surgem diversos programas de Mediação de Conflitos a partir de 1993 em centros educativos do País Vasco e Cataluña. Logo depois, implementa-se um extenso programa na Comunidade de Madrid, que é analisado por Seijo e González (2008). Segundo os autores, o programa implementado pelo Departamento de Orientación Escolar del Centro Regional de Innovación y Formación del Profesorado "Las Acacias" foi bem avaliado. O programa baseava-se em equipes de mediação, com um coordenador. Essas equipes eram constituídas por professores, alunos, equipe gestora, algumas vezes pais e pessoal não-docente. Quanto mais o coordenador se dedicava e dinamizava o grupo, mais positivas eram as experiências mediativas. A formação contínua e a inserção no Regimento Interno das escolas da mediação como instrumento demonstravam o interesse e a valorização pelo projeto.

No entanto, alguns pontos negativos foram destacados na pesquisa: falta de apoio ou de postura da equipe gestora frente à mediação; muitas vezes, a não participação dos orientadores (com formação em pedagogia ou psicologia) nas equipes de mediação; o número de pais e pessoal não-docente nas equipes era muito pequeno; a falta de fundamento e preparo para algumas equipes lidarem com os conflitos levando, muitas vezes, a assumirem posicionamentos reativos.

Para Seijo e González (2008) a postura da equipe gestora com relação à convivência é fundamental para se implementar um projeto de Mediação de Conflitos nas escolas. "La línea de gestión del centro impulsada por el equipo directivo es decisiva para que la mediación se ponga en práctica y se potencie 0 , por el contrario, se frene y se desestime" (Seijo \& González, 2008, p. 387).

$\mathrm{Na}$ Espanha, na região de Andaluzia, como resultado de dois projetos de intervenção educativa e investigação dirigidos por Ortega nos anos 90, SAVE (Sevilla Anti-Violencia Escolar) e ANDAVE (Andalucía Anti-Violencia Escolar), foram elaboradas propostas para a abordagem dos conflitos no âmbito educativo, integrando a mediação a algumas premissas. Uma das mais importantes era que se indicava a aplicação de técnicas de mediação em situações de conflito interpessoal, desaconselhando seu uso em caso de se ter indícios de violência, abusos, perseguição e/ou vitimização por alguma das partes (Del Rey \& cols., 2004). A mediação somente é possível e satisfatória quando os participantes podem sentir-se num mesmo plano e não se percebem submetidos a um desequilíbrio de poder. Em situações de violência escolar é necessária a utilização de outras técnicas que restituam o equilíbrio (por exemplo: Método Pikas em casos de bullying) e uma vez superada essa fase, no caso de persistir o conflito e na ausência de violência, poderia ser o momento de se tentar resolvê-lo com a mediação. Outra 
premissa importante para a mediação, resultado da inferência educativa sobre resultados de investigação (Monks, Ortega-Ruiz, \& Rodríguez-Hidalgo, 2008; Rodríguez-Hidalgo, Ortega-Ruiz, \& Zych, 2014), é a necessidade de contemplar os fatores étnico-culturais e socioeconômicos para a mediação intercultural necessária em conflitos em contextos pluriculturais. Quando os conflitos surgem entre protagonistas que se percebem entre si com códigos étnico-culturais e/ ou status socioeconômicos diferentes, podem ampliar-se e desembocar em situações de violência com conotações e efeitos além dos esperados numa situação de violência entre pessoas que compartilham a mesma identidade cultural. Quando o conflito acontece em contextos de desequilíbrio socioeconômico e contraposição de identidades étnico-culturais, os indivíduos dos grupos minoritários ou com menos recursos se encontram numa situação de maior risco psicossocial do que as de um grupo maioritário ou com mais recursos. Os membros das minorias estão mais expostos à vitimização de carácter étnico-cultural, podendo esta originar-se também entre membros de grupos minoritários que se percebem como competidores entre si (Monks, Ortega, \& Rodríguez, 2010). Aos efeitos já conhecidos da vitimização (dano à autoestima pessoal, stress, rompimento da rede social e isolamento etc.) agrega-se à vitimização étnico-cultural a degradação da autoestima sobre o grupo étnico-cultural de pertencimento, o sentimento de exclusão por sua identidade cultural própria e o afastamento de relações sociais com membros do "exogrupo" étnico-cultural e o recolhimento destas relações somente para dentro do "endogrupo" (Rodríguez, 2010). A vitimização étnico-cultural conduz assim a sentir-se objeto de discriminação - como indivíduo e como coletivo - o que produz um efeito desintegrador particularmente perigoso quando se origina no seio da instituição escolar. Esta forma de viver a diferença na escola atenta contra os princípios mais elementares que devem sustentar todo o seu projeto educativo: a inclusão, a interculturalidade e a construção social em igualdade de oportunidades.

Contudo, os países acima citados já têm uma trajetória consolidada nas experiências com a mediação de conflitos na escola. Na América Latina, experiências com a mediação escolar surgiram, em sua maioria, a partir de 2000. Um país que se destaca nesse campo é a Argentina, possuindo diversas experiências do gênero.

\section{Mediação de conflitos na escola: América do Sul}

Na América do Sul, segundo Gajardo (2004), quase todos os países contam com algumas experiências educativas focadas na convivência escolar e na prevenção da violência nas escolas. Algumas dessas experiências amparam-se na mediação e na resolução de conflitos dentro de suas propostas educacionais. Beatrice Avalos, em 2003, fez um levantamento sobre os programas e projetos desenvolvidos na América do Sul para a prevenção da violência escolar. Entre os países investigados estavam Argentina, Chile, Co- lômbia, Equador e Venezuela, que possuíam experiências com a resolução e a mediação de conflitos no campo educativo.

No caso do Chile, surgiram duas experiências nessa linha como resposta às manifestações de violências que começaram a ser observadas a partir do ano 2000. "Conversando es mejor. Resolución de conflictos en la escuela" foi um programa implementado na cidade de Santiago pela Fundación de Ayuda Social de las Iglesias Cristianas, a partir de julho de 2001, com prazo de finalização em 2005. O principal foco era a formação e a sensibilização de docentes, estudantes e advogados ligados à educação para a resolução de conflitos, por meio do diálogo e da comunicação. O projeto "Convivencia Escolar" foi implementado pelo Ministério de la Educación Nacional, Unidad de Apoyo a la Transversalidad, igualmente em 2001. Esse projeto pretendia trabalhar com práticas de prevenção e resolução de conflitos por meio dos objetivos transversais no currículo. Uma das ações baseava-se no fortalecimento de uma rede de professores que definiam, desenvolviam e avaliavam ações de uma educação para a convivência. Além disso, criavam comitês de convivência escolar democrática que serviam de apoio à equipe gestora, liderada pelo diretor da escola e com a participação de professores, pais e alunos (Avalos, 2003).

Atualmente, embora não existam experiências com mediação de conflitos escolares impulsionadas em nível nacional no Chile, ainda há um investimento para a formação para a convivência escolar e a resolução de conflitos, como pode ser verificado no material produzido "Conviviendo mejor en la escuela y en el liceo" pelo Ministério da Educación República de Chile, em 2010 (Esquinazi \& Navarro, 2010).

A Colômbia, assim como Brasil, Argentina e Peru, é um país que em 2003 já possuía uma política nacional legalmente instituída no que se refere à prevenção da violência nas escolas. "Colombia, afectada por una guerra interna de años con sus múltiples efectos sobre la convivencia escolar y la estabilidad de las acciones educativas, establece también una Política Educativa para la Formación Escolar en Convivencia en el año 2001" (Avalos, 2003, p.5).

"Mediadores de Conflictos Escolares" foi um projeto desenvolvido pelo "Programa de Convivencia y Derechos Humanos". Começou a ser implementado em 2000 e 2001, em 10 escolas do município de Itagüí, sendo financiado pela agência espanhola de cooperação Manos Unidas. Criava uma equipe de mediadores na escola, de no máximo 10 pessoas, representantes de todos os seguimentos da comunidade educativa (diretor, coordenador, professor, pai ou mãe, aluno, inspetor etc.). Durante o primeiro ano a metodologia de trabalho se baseava em construir espaços de reflexão sobre a lógica do conflito e sinalizar formas de intervenção. No segundo ano se construíam propostas de intervenção postas em prática com a participação de todos os integrantes da escola, inclusive o diretor. No terceiro ano se realizava o acompanhamento do processo, reavaliando e ajustando a proposta à realidade, permitindo que a instituição caminhasse de forma autônoma por meio das mudanças necessárias (Avalos, 2003). 
Avalos (2003) descreve que as atividades desse projeto baseavam-se em intercâmbio de experiências com todos os integrantes da equipe de mediação (quatro encontros ao ano), com o estudo dos aspectos conceituais e metodológicos, bem como o estabelecimento de tarefas a serem realizadas; reuniões mensais da equipe de mediação a fim de acompanhar as atividades realizadas e temas específicos de cada instituição; e três eventos acadêmicos e públicos ao ano para propiciar a reflexão coletiva sobre a criação de um ambiente democrático que o processo requeria.

Esse projeto foi finalizado; porém, ainda existem experiências pontuais nas escolas com a mediação de conflitos escolar. Em 2005, o Ministério da Educação da Colômbia implementou uma "Política educativa para la formación escolar para la convivencia", que estabelecia que no rol da equipe gestora houvesse a formação específica para a implantação de mecanismos da mediação, além de outros elementos para convivência entre pares, alunos e comunidade (Mineducación, 2005).

No Equador foi desenvolvido, em 2001, o projeto "La Mediación Escolar: Un Sistema Alternativo para Resolver Conflictos en la Comunidad Educativa" pela organização Defensa de los Niños Internacional, pela Projusticia e pelo Ministerio de Educación y Cultura. Na província de Pichincha, mais de 13 mil crianças foram preparadas para a resolução alternativa dos conflitos por meio de professores que eram tutores do programa, mais de 200 alunos foram preparados para a mediação de conflitos e foram formados comitês para mediação com os familiares dos alunos das escolas envolvidas. O projeto teve a duração de 22 meses (Avalos, 2003).

"Somos Ciudadanos" era o programa da CECODAP (organização social venezuelana para a promoção e defesa dos direitos das crianças e jovens) implementado no estado de Vargas, na Venezuela. O programa iniciou-se em setembro de 2001. A intenção era que crianças e jovens exercessem a cidadania por meio da participação e organização nas escolas, não apenas para a defesa dos direitos, mas também para o cumprimento dos deveres e a busca de soluções para os problemas individuais e coletivos. Assim, em 20 centros educativos participaram do programa 120 alunos como "Guardianes de la Ciudadanía" e como "Mediadores de Conflicto". Os professores igualmente eram preparados "en materia de Resolución de Conflictos, Mediadores de Conflicto en la Escuela, Reglamentos de Convivencia Escolar, Construcción de Proyectos de Convivencia, Educación y Participación Estudiantil, Programación de Actividades Públicas con Niños y Adolescentes" (Avalos, 2003, p. 82).

Avalos (2003) salienta que de acordo com a avaliação feita pelo Programa sueco "Save the Children" sobre o programa venezuelano, destacou-se entre outros elementos, que faltava a participação do meio familiar. Ainda hoje, a CECODAP utiliza técnicas de mediação de conflitos no interior de seus projetos em mais de 100 centros educativos na Venezuela (CECODAP, 2013).

Certamente o país da América do Sul que mais desenvolveu a mediação de conflitos foi a Argentina, que possui uma legislação específica para a convivência e a mediação escolar (Veiga, 2008). Em nível nacional, a Resolução de 20 de agosto de 1997, estabelece os "criterios básicos para el desarrollo de normas de convivencia en las instituciones escolares", recomendando-se que a mediação seja uma alternativa para se amenizar os conflitos escolares (Resolución n 62/97, 1997).

A Província de Chaco foi a primeira, em 2000, a desenvolver um projeto com a mediação de conflitos escolares, quando o Ministerio de Educación, Cultura, Ciencia y Tecnología criou a Lei 4711, implementando o "Plan Provincial de Mediación Escolar" (Zampa, 2009). Uma equipe interdisciplinar foi designada para formar professores, capacitadores e alunos de níveis pré-escolar, básico e médio nas técnicas de resolução de conflitos por meio da mediação e negociação em ambiente escolar (EICAME - Equipo Interdisciplinario Capacitador en Mediación Educativa) e o projeto foi efetivado como "Experiencias en Manejo de Conflictos y Mediación Escolar" (Avalos, 2003). Além disso, a intenção era que os pais participassem ativamente da escola, oportunizando tempo e espaço para que isso acontecesse. Igualmente se oportunizava espaço para que os professores discutissem os conflitos vivenciados e as possíveis intervenções. Segundo Avalos (2003), havia a preocupação de sobrepor a autoridade ao autoritarismo, buscando o apoio e o compromisso dos integrantes da comunidade escolar na tentativa de lidar com os conflitos.

O projeto encerrou-se em 2006; no entanto, a equipe interdisciplinar ainda atua com a formação docente contínua na Argentina e alguns outros países da América Latina como Chile, Paraguay, Uruguay, Ecuador, Panamá, México e Puerto Rico, em instituições públicas e privadas (EICAME, 2013).

Em setembro de 2003, o Ministerio de Educación, Ciencia y Tecnología de la Nación desenvolveu o "Programa Nacional de Mediación Escolar” (Resolución n 503), seguindo linhas muito semelhantes ao projeto desenvolvido na Província de Chaco. A Ley de Educación Nacional (Ley n. 26.206, 2006) de 2006, igualmente impulsionava ações para a mediação escolar estabelecendo que o Consejo Federal de Educación fixasse as disposições necessárias para "desarrollar prácticas de mediación que contribuyan a la resolución pacífica de conflictos” (Ley n. 26.206, Artigo 123 , inciso J).

Deste modo, escolas públicas, privadas, organizações não governamentais iniciavam o desenvolvimento de projetos, investigações e formações focando a mediação de conflitos em diversas províncias argentinas, como acontece em 23 de abril de 2009, na Província de Buenos Aires, que implementa a Ley de Mediación Escolar. Na Província de Córdoba (Argentina) difundiu-se um projeto de Hugo Caparros, convertido posteriormente na Lei 9801/97 do Honorable Consejo Directivo, sobre a "Implementación de la medición escolar em las escuelas municipales de la Ciudad de Córdoba". Porém, os resultados não foram os esperados e não houve continuidade no projeto (Veiga, 2008). 
Desde novembro de 2009, a Província de Córdoba (Argentina) possui como novo profissional o Coordinador de Curso. Com um rol de ações amplo, os Coordinadores de Curso atuam investigando a realidade escolar, conhecendo as situações, os problemas, auxiliando nas interações interpessoais, com negociações e acordos entre os diversos sujeitos, além de intervirem em ações que contribuam com o desenvolvimento pedagógico dos alunos (Ministerio de Educación de la Provincia de Córdoba, 2009 e 2011).

Chamados de mediadores pela própria mídia ${ }^{1}$, os Coordinadores de Curso ingressam nas escolas argentinas para suprir as novas necessidades que surgiram a partir da extensão da obrigatoriedade da escola secundária. As funções do Coordinador de Curso visam melhorar os processos de escolarização e de socialização dos estudantes, sobretudo aqueles que se encontram em condições de maior vulnerabilidade social. Em sua atuação não utilizam especificamente técnicas da mediação e resolução de conflitos, salvo algumas exceções, como é o caso do Professor Mediador Escolar e Comunitário no Brasil.

\section{Mediação de conflitos na escola: Brasil}

O Brasil igualmente possui uma trajetória com relação a projetos e programas inseridos nas políticas públicas que visam amenizar as violências nas escolas. Devido à intensidade de fatos ocorridos na década de 1990, o Ministério da Justiça do Brasil encarregou uma comissão de especialistas da Secretária de Direitos Humanos a elaborar diretrizes para a diminuição das manifestações violentas nas escolas (Avalos, 2003). O "Programa Paz nas escolas" foi difundido em nível nacional e focava a formação de professores e de policiais para lidarem com o tema da violência nas escolas. Outros programas e projetos foram desenvolvidos pelo governo federal, governos estaduais, municipais, bem como ações realizadas por organizações não-governamentais e outras instituições diversas. Dentre esses projetos e programas surgiram algumas experiências pontuais que tinham como foco a resolução e a mediação de conflitos escolares.

$\mathrm{Na}$ cidade do Rio de Janeiro, por exemplo, desenvolveu-se o projeto "Escolas de Mediadores", em 2000. A iniciativa seria capacitar alunos para que utilizassem as técnicas de mediação de conflitos com seus colegas. Esse projeto, que tinha como parceria o Instituto NOOS, Viva Rio - Balcão de Direitos, Mediare e Secretaria Municipal de Educação, foi aplicado em duas escolas públicas do Rio de Janeiro (Sales \& Alencar, 2004). Outras experiências pontuais, aplicadas em algumas escolas surgiram nas cidades de São Paulo (Ruotti, Alves, \& Cubas, 2006), de Porto Alegre (Santos, 2001) e no Estado do Ceará (Bezerra, 2008), entre outras.

\footnotetext{
1 Reportagem intitulada: "Coordinadores de curso, mediadores en la escuela". Publicada em 2 de dezembro de 2012, pela Redacción Prensa do Gobierno de la Provincia de Córdoba.Recuperado: 01 jun. 2013. Disponível: http://prensa.cba.gov.ar/educacion/ coordinadores-de-curso-mediadores-en-laescuela/.
}

Em junho de 2010, a Secretaria de Estado da Educação de São Paulo (SEESP), juntamente com a Fundação para o Desenvolvimento da Educação (FDE) e a Secretaria da Segurança Pública criam a função do "Professor Mediador Escolar e Comunitário" (PMEC). Em grande parte, essa função surgiu como resposta às manifestações de violência na escola, principalmente as propagadas indiscriminadamente pela mídia. Esse profissional deveria, entre outras funções, "adotar práticas de mediação de conflitos no ambiente escolar e apoiar o desenvolvimento de ações e programas de Justiça Restaurativa" (Resolução SE n. 19, 2010, art. 7º). Os PMECs seriam os professores responsáveis pelo desenvolvimento do Sistema de Proteção Escolar, um programa da SEESP. Quase mil professores de diferentes áreas de ensino poderiam atuar como PMECs nas escolas estaduais paulista em 2010. Hoje há mais de três mil PMECs atuando no Estado de São Paulo.

De acordo com a tese de Possato (2014), esse profissional não assume as funções de um mediador de conflitos, tampouco utiliza a Justiça Restaurativa, sendo que essas técnicas permanecem apenas na legislação e no nome dado a essa função na educação paulista. A pesquisa etnográfica realizada, acompanhando durante um ano as ações desse profissional, demonstrou que devido à falta de funcionários e diversos outros problemas estruturais no ensino público paulista, não foi possível que o PMEC desenvolvesse um projeto para amenizar as violências escolares. O PMEC assumia muitas funções outras que não eram as suas (diretor, secretário, inspetor, professor etc.) e possuía uma condição de trabalho aviltante.

Menezes (2012), em sua Dissertação de Mestrado sobre o PMEC, discute a mesma questão. Embora haja uma avaliação positiva dos sujeitos escolares, a autora destaca que esse profissional está incerto com relação a sua função no contexto escolar, e do mesmo modo que a pesquisa de Possato (2014), realiza outras funções, muitas vezes distantes de atribuições referentes ao seu trabalho. A autora destaca igualmente que os PMECs aprendem por tentativa e erro, construindo sua função aos poucos, sozinhos, sem ter muita segurança com relação a seu papel na escola. Identificando-se, algumas vezes, com "inspetores de luxo", outras vezes, como gestores, esses profissionais possuem um cargo transitório, sem estabilidade. Para Menezes (2012), um dos problemas principais foi a falta de preparo prévio dos PMECs para adentrarem nas escolas e a falta de estrutura das escolas para receberem esses professores, dados observados igualmente na pesquisa de Possato (2014). Deste modo, podemos avaliar que a Mediação de Conflitos Escolares no Brasil ainda faz parte de projetos e programas pontuais, que não são representativos em nível nacional.

\section{Discussão e conclusões}

Não é possível avaliar os resultados dos projetos e programas que envolvem a mediação de conflitos escolares na América do Sul. Muitos programas pesquisados que 
foram avaliados positivamente foram encerrados e outros continuam com instituições privadas; portanto, parece-nos ser urgente a produção de estudos que contribuam para melhor compreendermos o alcance de tais programas nas realidades escolares.

Porém, o que destacamos é que a maioria dos programas e projetos envolvendo a mediação escolar possuíam equipes de mediadores e não se concentravam em uma única pessoa. Outro fator é que em alguns casos a convivência passava a ser incorporada ao currículo, como um tema transversal. No caso colombiano, o gerenciamento dos conflitos escolares passou a ser uma competência exigida ao diretor.

O fato é que há uma expansão de programas e projetos ao longo dessa última década que acreditam que a mediação dos conflitos na escola seja a solução para a amenização das violências escolares. Na verdade, a mediação de conflitos é uma estratégia entre outras, que podem auxiliar as escolas e, portanto, não pode ser o elemento central de tantos programas educacionais. Além de ser uma estratégia entre outras, destacamos que a mediação de conflitos depende da sociedade em que é introduzida para obter resultados ou não. Cada sociedade possui suas características e conflitos próprios, sendo necessária uma investigação extensa para saber qual seria a melhor atuação em determinada sociedade ou realidade escolar.

Com relação às técnicas de mediação de conflitos, nos parece estranho que haja tanto investimento em um processo que deveria ser valorizado no processo formativo de qualquer sujeito, principalmente no interior das escolas: o diálogo. É certo que há técnicas específicas para a comunicação; no entanto, parece-nos que esta é uma tentativa de trazer o diálogo às relações humanas dentro dos contextos educativos, algo que Paulo Freire (1979) já estabelecia como elemento fundamental para a educação, no final da década de 1970. Para Freire, a "educação é comunicação, é diálogo, na medida em que não é a transferência de saber, mas um encontro de sujeitos interlocutores que buscam a significação de significados" (Freire, 1979, p. 69). Deste modo, continua sendo necessário que se busquem estratégias, políticas públicas e profissionais específicos para que esse diálogo aconteça.

Longe de buscar soluções simplistas, podemos evidenciar que o primeiro passo para uma política pública que procure amenizar as violências escolares deveria pertencer à alçada da educação. A maioria dos países apontados neste estudo tem na área judicial o nascimento de seus projetos, o que já aponta uma judicialização da educação. Porém, no Brasil torna-se pior, pois o programa para se amenizar as violências nas escolas é um projeto conjunto com a Secretaria de Segurança Pública, tornando a educação um caso de polícia.

Acreditamos que a escola é um espaço privilegiado no que se refere à heterogeneidade e que seriam necessários mais estudos para se compreender seus contextos. Somente a partir de aprofundamento nas pesquisas, valorização dos profissionais da escola e formação, no sentido de compreender a realidade local e intervir junto à comunidade com projetos e soluções conjuntas, além do investimento na participação dos alunos e da comunidade nas decisões da escola, por meio das assembleias, Grêmios estudantis, se poderia começar a pensar um projeto para amenização dos conflitos e das violências nas escolas. O enfrentamento e resolução de conflitos em contextos escolares pluriculturais faz necessária uma mediação intercultural, que para além da mediação interpessoal contemple como base a compreensão, o diálogo e o desenvolvimento comunitário entre culturas respeitando e integrando a diversidade étnico-cultural e socioeconômica (Ortega \& cols., 2004). Mais concretamente, em torno do uso da mediação interpessoal, se deveriam também contemplar programas de formação para profissionais da educação sobre conflitos e outras causas difusas que repercutem negativamente na convivência escolar, assim como sobre as estratégias mais apropriadas para sua prevenção e tratamento.

\section{Referências}

Alzate, R. S. H. (1999), Enfoque global de la escuela como marco de aplicación de los programas de resolución de conflictos. Em F. Brandoni (Org.), Mediación escolar: propuestas, reflexiones y experiencias (pp. 31-55). Buenos Aires: Ediciones Paidós Iberica.

Apple, M. (2006). Ideologia e Currículo. Porto Alegre: ArtMed.

Aréchaga, P., Brandoni, F., \& Finkelstein, A. (2004), Acerca de La Clínica de Mediación. Relato de Casos. Colección Visión Compartida. Argentina: Librería Histórica.

Avalos, B. (2003). Prevención de la violencia en escuelas de América del Sur: catastro de programas y proyectos. Santiago, Chile: PREAL.

Bezerra, S. M. A. (2008). Educação em direitos humanos e a mediação escolar como instrumento que possibilita a prática do aprendizado em direitos humanos. Dissertação de Mestrado. Centro de Ciências Jurídicas. Unifor - Universidade de Fortaleza.

Bonafé-Schmitt, J. (2009). Mediação, conciliação, arbitragem: técnicas ou um novo modelo de regulação social. Em A. M. C. Silva \& Moreira, M. A. (Orgs.), Formação e Mediação Sócio-educativa. Perspectivas teóricas e práticas (pp.15-40). Porto: Areal Editores.

CECODAP (2013). Sobre CECODAP. Recuperado: 12 jun. 2013. Disponível: http://www.cecodap.org.ve/nosotros.php.

Coordinadores de curso, mediadores en la escuela (2012, 2 de dezembro). Redacción Prensa do Gobierno de la Provincia de Córdoba. Recuperado: 01 jun. 2013. Disponível: http://prensa. cba.gov.ar/educacion/coordinadores-de-curso-mediadores-enlaescuela

Del Rey, R., Sánchez, V. \& Ortega, R. (2004). Resistencias, conflictos y dificultades en la convivencia escolar. Em R. Ortega \& R. Del 
Rey (Orgs.), Construir la Convivencia (pp. 193-210). Barcelona: Edebé.

Equipo Interdisciplinario Capacitador en Mediación Educativa [EICAME] (2013). Ley de Mediación. Recuperado: 16 jun. 2013. Disponível: http://usuarios.arnet.com.ar/abrjos/Ley4711.htm.

Esquinazi, P. Y. \& Navarro, J. G. (2010). Conviviendo mejor en la escuela y en el liceo. Em Manual sobre Convivencia Escolar dirigido a todos los integrantes de la Comunidad Educativa. Chile: Ministerio de Educación República de Chile.

Fernández, I. (1998). Prevención de la violencia y resolución de conflictos: el clima escolar como factor de calidad. Madrid: Narcea S. A.

Feshbach, S. (2001). Ethnic Diversity and the Interaction of Social Prejuice and Aggression. Aggressive Behavior, 27(3), pp. 206-207.

Freire, I. (2010). Mediação em Educação em Portugal. Em J. A. Correia \& A. M. Silva (Orgs.), Mediação:(d)os contextos e (d)os actores (pp. 59-70). Porto: LibPsi, Colecção Ciências da Educação.

Freire, M. (1992). O que é grupo? Em E. P. Grossi \& J. Bordin (Orgs.), Paixão de Aprender I. Petrópolis, RJ: Vozes.

Freire, P. (1979). Extensão ou comunicação? (4a. ed.). Rio de Janeiro: Paz e Terra.

Kolb, D. (1994). When Talk Works: Profiles of Mediators. San Francisco, CA: Jossey Bass.

Gajardo, M. (2004). Resolución de conflictos y mediación en la escuela: experiencias sudamericanas. Formas \& Reformas de la Educacion. Serie Prevención de la Violencia Escolar, 2 (2). Santiago - Chile: PREAL. Recuperado: 02 jun. 2013. Disponível: http://www.ocse.org.mx/pdf/26_PREAL.pdf.

Garcia Costoya, M. (2004). Orientaciones para el diseño e implementación de proyectos. Buenos Aires: Ministerio de Educación Ciencia y Tecnología de la Nación.

Ley n. 26.206 (2006). Ley de Educación Nacional. Buenos Aires: Ministerio de Educación Presidencia de la Nación Argentina.

Littlejohn, S. \& Domenici, K. L. (1999). Objetivos e Métodos de Comunicação na Mediação. Novos paradigmas em mediação (pp. 209-223). Porto Alegre: Artmed.

Maffesoli, M. (1987). O Tempo das Tribos: o declínio do individualismo nas sociedades de massa. Rio de Janeiro: Forense-universitária.

Menezes, E. C. A. (2012). Mediação de conflitos nas escolas públicas da diretoria de ensino região de Assis: estudo de caso centrado na função de professor mediador escolar e comunitário. Dissertação de Mestrado. Programa de Mestrado Em Educação. Universidade do Oeste Paulista.
Mineducación. Ministerio de Educación Nacional República de Colombia. (2005). Política educativa para la formación escolar para la convivencia. Recuperado: 12 jun. 2013. Disponível: http:// www.mineducacion.gov.co/1621/articles-90103_archivo_pdf.pdf.

Ministerio de Educación de la Provincia de Córdoba (2009). Documento de la Dirección General de Enseñanza Media de la pcia. de córdoba El coordinador de curso: roles y funciones como figura institucional en la escuela secundaria. Córdoba.

Ministerio de Educación de la Provincia de Córdoba (2011). Construyendo el Oficio del Coordinador de Curso. Documento para la discusión producido a partir de las "Jornadas de Encuentro y Acompañamiento de los Coordinadores de Curso". Secretaría de Educación. Dirección General de Educación Media. Subdirección General de Educación Media.

Monks, C., Ortega-Ruiz, R., \& Rodríguez-Hidalgo, A. J. (2008). Peer victimization in multicultural schools in Spain and England. European Journal of Developmental Psychology, 5, 507-535.

Monks, C., Ortega, R., Rodríguez, A. J. (2010). Sociedades pluriculturales y violencia escolar racista. Em R. Ortega (Org.), Agresividad injustificada, "bullying" y violencia escolar (pp. 233250). Madrid: Alianza Editorial.

Morgado, C. \& Oliveira, I. (2009). Mediação em contexto escolar: transformar o conflito em oportunidade. Exedra Revista Científica, n.1, 43-55.

Ortega, R. \& Del Rey, R. (2003). La violencia escolar: Estrategias de prevención. Barcelona: Graó.

Ortega-Ruiz, R. \& Del Rey, R. (2002). Estratégias educativas para a prevenção da violência (Ozório, J., Trad.). Brasília: Unesco/UCB.

Ortega, R., Rodríguez, A. J., \& Larrasoain, A. (2004), Interculturalidad y convivencia escolar. Em R. Ortega \& R. Del Rey (Orgs.), Construir la Convivencia (pp. 41-58). Barcelona: Edebé.

Ortega, R. \& Rodríguez, A. J. (2003). Violencia Escolar: un marco conceptual para la investigación e intervención psicoeducativa. Em III Congreso Internacional de Educación "del conflicto y la violencia, a la convivencia y la paz” (pp.93-100). Santa Fe: Universidad Católica de Santa Fe, Argentina.

Possato, B. C. (2014). O "Professor Mediador Escolar e Comunitário": uma mirada a partir do cotidiano escolar. Tese de doutorado, Faculdade de Educação, Unicamp: Campinas, SP.

Resolución $n^{\circ} 503$ de septiembre de 2003 (2003). Crease el Programa Nacional de Mediación Escolar. Ministerio de Educación y Deportes. Argentina.

Resolución n 62/97 de 20 de Agosto de 1997 (1997, 20 de agosto). Se establecen como principios fundamentales de la educación, la convivencia pluralista, la participación, el derecho de los alumnos 
a ser respetados en su integridad, dignidad, libertad de conciencia y de expresión; y en su art. $42^{\circ}$, por la cual se determinan los distintos miembros de la comunidad educativa y las competencias de la misma. C.F.C. y E. Consejo Federal de Cultura y Educación. Secretaría General.

Resolução SE $n^{\circ}$ 19, de 12 de fevereiro de 2010 (2010, 12 de fevereiro). Institui o Sistema de Proteção Escolar na rede estadual de ensino de São Paulo e dá providências correlatas. São Paulo: Diário Oficial, Poder Executivo, Seção I, 120 (30), p. 29.

Rodríguez, A. J. (2010). More than pride at stake: discrimination and racism. Em R. Ortega, Del Rey, R., \& P. Rojas (Orgs.), Be Young: risks and opportunities. Unigraf, Córdoba.

Rodríguez-Hidalgo, A. J., Ortega-Ruiz, R., \& Zych, I. (2014). Peer Victimization and Ethnic-Cultural Peer Victimization: Self-Esteem and School Relations between Different Cultural Groups of Students in Andalusia. Revista de Psicodidáctica, 19 (1), 191-210.

Ruotti, C., Alves, R., Cubas, V. O. (2006). Violência na escola: um guia para pais e professores. São Paulo: Andhep: Imprensa Oficial do Estado de São Paulo.

Sales, L. M. M. \& Alencar, E. C. O. (2004). Mediação de conflitos escolares: uma proposta para a construção de uma nova mentalidade nas escolas. Pensar, 9 (9), 89-96.
Santos, J. V. T. (2001), A violência na escola: conflitualidade social e ações civilizatórias. Educação e Pesquisa, 27 (1),105-122.

Seijo, J. C. T. \& González, A. G. (2008). A investigación evaluativa sobre el programa de mediación de conflictos en centros escolares. Revista de Educación, 347, 369-394.

Seijo, J. C. T. (2001). Mediación de conflictos en instituciones educativas. Manual para la formación de mediadores. Madrid: Ed. Narcea.

Silva, A. M. C. (2011). Mediação e(m) educação: discursos e práticas. Revista Intersaberes, Curitiba, 6 (12), 249-265.

Vecchi, S. \& Grego, S. (1999). Proposta reflexiva na prática da mediação. Em: S. Littlejohn \& K. L. Domenici (Orgs.), Novos paradigmas em mediação (pp.243-255). Porto Alegre: ArtMed.

Veiga, R. O. (2008). De la mediación a la mediación educativa. Tese de doutorado, Universidad de Morón, Argentina.

Zampa, D. M. (2009). ¿De qué hablamos cuando hablamos de Mediación? Revista de Mediación, 2 (3), 38-44.
Recebido em: 24/03/2015

Reformulado em: 13/08/2015

Aprovado em: 05/08/2016

\section{Sobre os autores}

Beatris Cristina Possato (biapossato@hotmail.com)

Doutora pela Faculdade de Educação da UNICAMP. Pesquisadora do grupo Violar (FE- Unicamp). Atualmente é Pós-doutoranda na Faculdade de Educação da Universidade da Cidade de São Paulo (UNICID) e bolsista CAPES.

Antonio J. Rodríguez-Hidalgo (m92rohia@uco.es)

Professor Contratado Doutor do Departamento de Psicologia da Universidade de Córdoba (Espanha), Diretor da Cátedra de Cooperación al Desarrollo de la Universidad de Córdoba e membro do grupo de investigação LAECOVI.

\section{Rosario Ortega-Ruiz (ed1orrur@uco.es)}

Catedrática da Universidade de Córdoba (Espanha), Professora Visitante na Universidade de Greenwich (Reino Unido) e diretora do grupo de investigação LAECOVI com vários projetos de investigação nacionais e internacionais.

Dirce Djanira Pacheco e Zan (dircezan@unicamp.br)

Professora Doutora da Faculdade de Educação da UNICAMP - Departamento de Ensino e Práticas Culturais (DEPRAC) e Diretora da Faculdade de Educação da mesma Universidade. É membro da diretoria do CEDES desde 2007 e do Conselho Técnico Científico da Capes/Educação Básica.

Apoio financeiro: Este artigo é resultado da bolsa CAPES - Processo n 3900/13-4, Programa de Doutorado Sanduíche no Exterior realizado em Córdoba, na Espanha. 